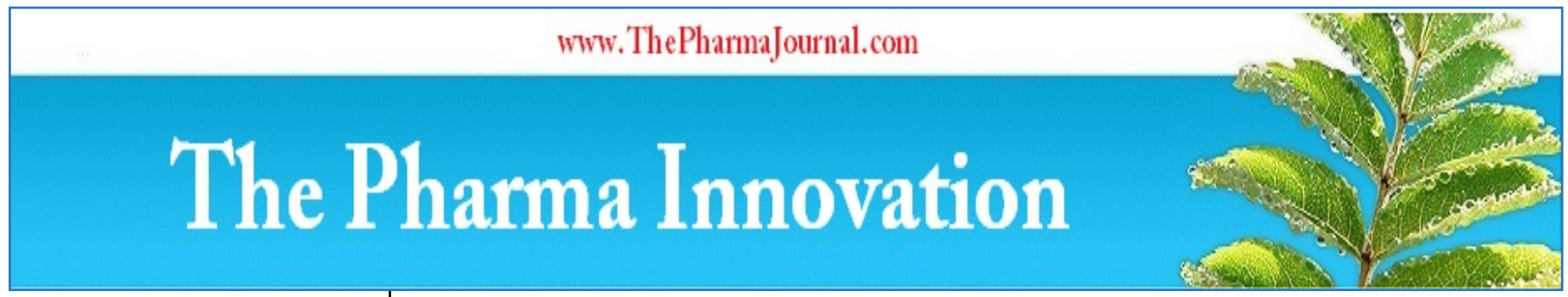

ISSN (E): 2277 - 7695

ISSN (P): 2349-8242

NAAS Rating: 5.23

TPI 2021; SP-10(8): 437-442

(C) 2021 TPI

www.thepharmajournal.com

Received: 10-06-2021

Accepted: 12-07-202

Smruti Rekha Panigrahi

Department of Family Resource

Management, Collage of

Community Science

Assam Agricultural University,

Jorhat, Assam, India

Dr. Ruplekha Borah

Professor, Dean, Collage of

Community Science

Assam Agricultural University,

Jorhat, Assam, India

Dr. Bijoylaxmi Bhuyan

Assistant Professor, Department

of Family Resource

Management, Collage of

Community Science

Assam Agricultural University,

Jorhat, Assam, India

Corresponding Author

Smruti Rekha Panigrahi

Department of Family Resource

Management, Collage of

Community Science

Assam Agricultural University,

Jorhat, India

\section{Musculoskeletal disorder \& perceived exertion among papad making women workers of Ganjam district, Odisha}

\author{
Smruti Rekha Panigrahi, Dr. Ruplekha Borah and Dr. Bijoylaxmi \\ Bhuyan
}

DOI: https://doi.org/10.22271/tpi.2021.v10.i8Sg.7293

\begin{abstract}
Aim and Objective: To analyse the work related musculoskeletal disorder prevalent among women workers involved in papad making activity. An observational survey was carried out among 120 female workers carrying out papad making activity on a daily basis. Interview cum observation method was used for data collection. Further chi square analysis was done to determine the association between variables. Result: Musculoskeletal disorder was the major health problems of the workers. Analysis of MSDs revealed that hand pain (98.3\%) was more predominant followed by wrist (95.8\%) buttock (95\%) and others.
\end{abstract}

Keywords: musculoskeletal disorder, papad, perceived exertion

\section{Introduction}

MSDs are common health problems throughout the world. According to the Canadian Centre for Occupational Health and Safety (2019), Work related Musculoskeletal Disorders (WMSDs) arise from arm and hand movements such as bending, straightening, gripping, holding, twisting, clenching and reaching. These normal movements are not harmful while performing the common activities in daily routine. What makes them risky in the working environment is their continual repetition, regularly, in a compelling way, and most important is the slow pace of muscle relaxation due to lack of time for the recovery. WMSDs are related with work designs that include: Fixed or static body postures, continual repetition of movements, force concentrated on small parts of the body such as hand or wrist, a pace of work that does not allow sufficient recovery between movements. Assessment of exposure levels to MSD risk factors can be an appropriate base for planning and implementing interventional ergonomics programs in the workplace (Singh, 2010) ${ }^{[7]}$. WMSDs usually occur when there is a mismatch between the physical requirement of the job and the physical capacity of the human body. Neck position and trunk position were found to be the major contributing factors for developing WMSD among the workers (Prasuna, 2013). Thus, assessment of posture and corrective measures in terms of ergonomics should be adopted so that the workers can maintain a neutral position, which would automatically make them more efficient and the cases of WMSDs can be avoided in the working places. Since this business requires a very low initial capital and does not involve hi-tech equipments and provides employment opportunities to many workers, especially women, thereby enabling them to be self-dependent and also contribute to their family income. As cottage industry this business is usually prevalent at household level, cluster level and also in few larger units in Ganjam district of Odisha. Most of the units were of subsistence level and almost all the sub activities of papad making were done manually with dominant participation of women. Cases of WMSDs were more common in these work places as the workers had to spend long hours, maintaining awkward postures, while making the papads. As this business of papad making is one of the profit making businesses for the people hence prioritizes the importance of ergonomic study in these work places so as to reduce the risk of harm or injury among the workers to ensure their safety and increase their efficiency. Ergonomics has a vital role to be played in this sector for making a safe and comfortable workplace for the people and also increasing productivity. The awkward postures maintained by these women during work for longer duration, have resulted in increased cases of WMSDs and have been detrimental to their health over a longer duration. 
Since earlier times, people have been suffering from WMSDs but due to the circumstances or their ignorance, these were not in open discussion. But in recent past and presently many studies were done to focus light on the prevalence of work related musculoskeletal disorders in the workplaces. Priority has been given to the cottage and small scale industries, where maximum work is being done by people manually. Ergonomics has been given priority while designing and manufacturing any equipment, especially agriculture related equipments for easing the labour of the farmers and increasing the total productivity. The purpose of this study was to find out perceived exertion and WMSDs prevailing among the workers of papad making industry in Ganjam district and suggest some ergonomic measures so that a safe, secure and comfortable work place can be created and the chances of WMSDs can be reduced, thereby increasing the overall efficiency of the work.

\section{Methods \& Materials}

The present study was carried out at Ganjam district, Berhampur city. The sample for the study was selected by following purposive cum proportionate allocation technique. Ganjam district was selected purposively due to the ease of researcher in collecting data. As the study is on papad making, Ganjam district is famous for papad making activity. Berhampur city was selected purposively. As this city is famous for its different variety of handmade papad. A total number of 120 samples were selected for the study by probability proportionate to size method.

\section{Reference period}

Reference period from 2018-2020.

\section{Method of data collection}

For the study, interview cum observation method was used for collection of data. Data were collected personally by the researcher. All the respondents were interviewed on pre tested structured schedule. Care was taken that only reliable and valid information were being noted down in the schedule. For posture analysis still photographs and video technique was used along with careful observation while performing different activities of papad making women. For personal and demographic profile data collected and analyzed on the basis of frequency and percentage. Extent of involvement defined as women's participation in papad making activity and was assessed in terms of 'daily', 'weekly', 'monthly'.

\section{Rating of perceived exertion}

On the basis of rating scale of perceived exertion (RPE) subjective rating of feeling of tiredness was categorized as follows A modified rating scale of perceived exertion (RPE), developed by Varghese et al. (1994), based on Borg's 10 point scale (Borg's 1982) was adopted to measure the perceived exertion in terms of Very light (1), light (2), moderately heavy (3), heavy (4), very heavy (5).

Work related musculoskeletal disorder among the respondents 4 point modified continuum scale was used (No pain=0), (Mild pain=1), (Moderate pain=2), (Severe pain=3) to calculate the intensity of musculoskeletal pain perceived among the workers.

\section{Identification of Body Parts Discomfort was done using Nordic Body Map and Ranking}

To identify the area of discomforts among the women respondents Nordic Body Map (NBM) was used, NBM consist of different body parts in a sequence starting from neck to feet. A five-point rating scale of (Corlett and Bishop, 1976) was used (No discomfort $=1$ ), (Just Noticeable discomfort=2), (Noticeable discomfort=3), (Tolerable discomfort=4), (Intolerable discomfort=5).

\section{Results \& Discussion}

Assessment of data on personal and demographic characteristics showed that 40.8 percent worker belonged to 30-40 years' age group and most of (73.3 percent) the respondents were found to be married (Table 1). But larger number (60 percent) workers were uneducated with papad making activity as the main occupation for 33.3 percent with 87.5 percent respondents having monthly income of Rs. 30005000 .

Table 1: Distribution of respondents according to their personal and demographic profile

\begin{tabular}{|c|c|c|c|}
\hline Sl. No. & Particulars & Frequency (f) & Percentage (\%) \\
\hline \multirow[t]{6}{*}{1} & Age of the respondents & & \\
\hline & $18-25$ & 17 & 14.2 \\
\hline & $25-30$ & 31 & 25.8 \\
\hline & $30-40$ & 49 & 40.8 \\
\hline & $40-50$ & 21 & 17.5 \\
\hline & $>50$ & 2 & 1.7 \\
\hline \multirow[t]{4}{*}{2} & Marital status & & \\
\hline & Unmarried & 16 & 13.3 \\
\hline & Married & 88 & 73.3 \\
\hline & Widow & 16 & 13.3 \\
\hline \multirow[t]{4}{*}{3} & Educational qualification & & \\
\hline & Uneducated & 72 & 60.0 \\
\hline & Primary school & 29 & 24.2 \\
\hline & High school & 19 & 15.8 \\
\hline \multirow[t]{6}{*}{4} & Main occupation & & \\
\hline & Unemployed & 40 & 33.3 \\
\hline & Farming & 38 & 31.7 \\
\hline & Business & 22 & 18.3 \\
\hline & Service & 11 & 9.2 \\
\hline & Any other & 9 & 7.5 \\
\hline \multirow[t]{4}{*}{5} & Income per month & & \\
\hline & $<3000$ & 8 & 6.7 \\
\hline & $3000-5000$ & 105 & 87.5 \\
\hline & $>6000$ & 7 & 5.8 \\
\hline
\end{tabular}


Extent of involvement of women in papad making activity (years of involvement)

It was revealed in Table 2 that, 44.1 percent of respondents were found to be working in the papad making industry for 15 years, followed by 36.7 percent respondents for 6-10 years, 15.8 percent respondents for 11-15 years and 2.5 percent for
21-25 years. It was also found that the maximum number of 20 percent of respondents between the age group 30-40 years had worked for 16-20 years in the papad making industry. It was observed that cent percent of women carried out papad making activity daily.

Table 2: Distribution of respondents of different age groups according to years of involvement $(n=120)$

\begin{tabular}{|c|c|c|c|c|c|}
\hline Age group & $\mathbf{1 - 5}$ years & $\mathbf{6 - 1 0}$ years & $\mathbf{1 1 - 1 5}$ years & $\mathbf{1 6 - 2 0}$ years & $\mathbf{2 1 - 2 5}$ years \\
\hline $18-25$ & 15 & 1 & 1 & - & - \\
\hline$(\mathrm{n}=17)$ & $(12.5)$ & $(0.8)$ & $(0.8)$ & & \\
\hline $25-30$ & 16 & 11 & 3 & - & 1 \\
\hline$(\mathrm{n}=31)$ & $(13.3)$ & $(9.2)$ & $(2.5)$ & & $(0.8)$ \\
\hline $30-40$ & 19 & 24 & 6 & - & - \\
\hline$(\mathrm{n}=49)$ & $(15.8)$ & $(20.0)$ & $(5.0)$ & & 1 \\
\hline $40-50$ & 2 & 8 & 9 & 1 & $(0.8)$ \\
\hline$(\mathrm{n}=21)$ & $(1.7)$ & $(6.7)$ & $(7.5)$ & - & 1 \\
\hline$>50$ & 1 & - & - & & $(0.8)$ \\
\hline$(\mathrm{n}=2)$ & $(0.8)$ & & & & \\
\hline
\end{tabular}

\section{Rating of perceived exertion in papad making activity}

- Dough making: Data in Table 3 revealed that majority (80.8 percent) respondents perceived that 'dough making' was a very light sub activity of papad making process, followed by 16.7 percent perceived it to be light, 1.7 percent perceived it to be very heavy and 0.8 percent perceived it to be moderately heavy sub activity of papad making process, so overall it was perceived as a very light sub activity of papad making activity with mean score of 1.25
- Ball making: According to Table 3, majority of the respondents (50.5 percent) perceived that 'ball making' was a moderately heavy sub-activity of papad making process, followed by 41.7 cent perceived it to be light, 5 percent perceived it to be heavy, 2.5 percent perceived it to be very light and 0.8 percent perceived it to be a very heavy subactivity of papad making process. With a mean score of 2.6, it is clear that ball making was perceived to be a moderately heavy sub-activity of papad making process.

Table 3: Distribution of respondents according to perceived exertion in papad making activity

\begin{tabular}{|c|c|c|c|c|c|}
\hline Sl. No & Papad making & Frequency (f) & Percentage (\%) & Total score & Mean RPE \\
\hline 1 & Dough making & & & & \\
\hline & Very light (1) & 97 & 80.8 & 97 & \multirow{5}{*}{1.25} \\
\hline & Light (2) & 20 & 16.7 & 40 & \\
\hline & Moderately heavy (3) & 1 & .8 & 3 & \\
\hline & Heavy (4) & - & & & \\
\hline & very heavy (5) & 2 & 1.7 & 10 & \\
\hline \multirow[t]{6}{*}{2} & Ball making & & & & \\
\hline & Very light (1) & 3 & 2.5 & 3 & \multirow{5}{*}{2.6} \\
\hline & Light (2) & 50 & 41.7 & 100 & \\
\hline & Moderately heavy (3) & 60 & 50.0 & 180 & \\
\hline & Heavy (4) & 6 & 5.0 & 24 & \\
\hline & very heavy (5) & 1 & .8 & 5 & \\
\hline \multirow[t]{6}{*}{3} & Rolling & & & & \\
\hline & Very light (1) & 1 & .8 & 1 & \multirow{5}{*}{4.46} \\
\hline & Light (2) & 1 & .8 & 2 & \\
\hline & Moderately heavy (3) & 2 & 1.7 & 6 & \\
\hline & Heavy (4) & 53 & 44.2 & 212 & \\
\hline & very heavy (5) & 63 & 52.5 & 315 & \\
\hline \multirow[t]{6}{*}{4} & Drying & & & & \\
\hline & Very light (1) & 8 & 6.7 & 8 & \multirow{5}{*}{2.25} \\
\hline & Light (2) & 88 & 73.3 & 176 & \\
\hline & Moderately heavy (3) & 12 & 10.0 & 36 & \\
\hline & Heavy (4) & 10 & 8.3 & 40 & \\
\hline & very heavy (5) & 2 & 1.7 & 10 & \\
\hline \multirow[t]{6}{*}{5} & Packaging & & & & \\
\hline & Very light (1) & 29 & 24.2 & 29 & \multirow{5}{*}{2.1} \\
\hline & Light (2) & 53 & 44.2 & 106 & \\
\hline & Moderately heavy (3) & 38 & 31.7 & 114 & \\
\hline & Heavy (4) & 1 & .8 & 4 & \\
\hline & very heavy (5) & - & - & & \\
\hline
\end{tabular}

- Rolling: Data in Table 3 depicted that the majority of 52.5 percent perceived 'rolling' as a very heavy sub-activity, 44.2 percent respondent perceived it to be a heavy sub- activity, 1.7 percent perceived it to be moderately heavy and 0.8 percent perceived to be both light and very light subactivity of papad making process. Mean score of 4.46 clearly 
says that rolling was perceived to be a very heavy sub-activity of papad making process.

- Drying: Data in Table 3 revealed that 73.3 percent respondents perceived 'drying' to be a light sub-activity, followed by 10 percent perceive it to be moderately heavy, 8.3 percent perceive it to be heavy, 6.7 percent perceive it to be very light and 1.7 percent perceive that drying was a very heavy sub-activity of papad making process. A mean score of 2.25 reveals that Drying was perceived to be light sub-activity of papad making process.

- Packaging: According to the data in Table 3, 44.2 percent of respondents perceived 'packaging' to be a light sub-activity, 31.7 percent perceived it to be moderately heavy, 24.2 percent perceived it to be very light and 0.8 percent perceived that packaging was a heavy sub-activity of papad making process. A mean score of 2.1 revealed that the packaging was perceived to be light sub-activity of papad making process. Out of these five processes 'rolling' with the highest mean score of 4.46 was perceived to be a very heavy sub-activity of papad making process. As the respondents need to sit in the scorching sun in a continuous posture for a longer time, so respondents perceive it to be a very heavy subactivity.

\section{Work related musculoskeletal disorder among the respondents}

Data from Table 4 revealed that 10.8 percent respondents complained about moderate pain in 'neck' followed by 6.7 percent complained about mild pain. About 31.7 percent workers complained about mild pain followed by 25 percent complained about moderate pain and 5 percent respondents perceived severe pain in 'shoulder'. Majority of 85.8 percent complained of moderate pain in 'upper and mid back' followed by 4.2 percent complained about mild pain. 5.8 percent respondents complained about moderate 'upper and lower arm’ pain. About 4.2 percent complained of moderate pain followed by 2.5 percent perceived severe pain in 'lower back'. Majority of 59.2 percent perceived moderate pain in 'buttock' followed by 19.2 percent complained of severe pain and $16.7 \%$ perceived mild pain. Moderate 'knee' pain was perceived by 25 percent respondents followed by 19.2 percent perceived mild pain followed by 7.5 percent perceived severe pain.

Table 4: Percentage distribution of musculoskeletal pain among the workers

\begin{tabular}{|c|c|c|c|c|c|c|c|c|c|}
\hline \multirow{2}{*}{ Sl. No } & \multirow{2}{*}{ Body Parts } & \multicolumn{2}{|c|}{ No Pain=0 } & \multicolumn{2}{c|}{ Mild pain=1 } & \multicolumn{2}{c|}{ Moderate pain=2 } & \multicolumn{2}{c|}{ Severe pain=3 } \\
\cline { 3 - 10 } & & $\mathbf{F}$ & $\mathbf{0}$ & $\mathbf{F}$ & $\mathbf{\%}$ & $\mathbf{F}$ & $\mathbf{\%}$ & $\mathbf{F}$ & $\mathbf{\%}$ \\
\hline 1 & Neck & 99 & 82.5 & 8 & 6.7 & 13 & 10.8 & - & - \\
\hline 2 & Shoulder & 46 & 38.3 & 38 & 31.7 & 30 & 25.0 & 5 & 5.0 \\
\hline 3 & Upper back & 12 & 10.0 & 5 & 4.2 & 103 & 85.8 & - & - \\
\hline 4 & Upper arms & 113 & 94.2 & - & - & 7 & 5.8 & - & - \\
\hline 5 & Mid back & 12 & 10.0 & 5 & 4.2 & 103 & 85.8 & - & - \\
\hline 6 & Lower arms & 113 & 94.2 & - & - & 7 & 5.8 & - & - \\
\hline 7 & Lower back & 112 & 93.3 & - & - & 5 & 4.2 & 3 & 2.5 \\
\hline 8 & Buttocks & 6 & 5.0 & 20 & 16.7 & 71 & 59.2 & 23 & 19.2 \\
\hline 9 & Knees & 58 & 48.3 & 23 & 19.2 & 30 & 25 & 9 & 7.5 \\
\hline
\end{tabular}

\section{Identification of Body Parts Discomfort among women involved in papad making activity}

Data from Table 5 revealed that 10.8 percent respondents complained about tolerable discomfort in the lower part of the neck, followed by 6.7 percent complained about noticeable discomfort, where as 82.5 did not find any discomfort. 31.7 percent complain noticeable discomfort in both left and right shoulders, followed by 25 percent were found to have tolerable discomfort, only 5 percent respondents complain about intolerable discomfort, but 38.3 percent did not find any discomfort in left and right shoulder. A majority of 85.8 percent complained about tolerable discomfort in the back, followed by 4.2 found to have noticeable discomfort, only 10 percent did not complain about any discomfort in the back. Tolerable discomfort in buttock was a complaint from 59.2 percent respondent, whereas 19.2 percent complain about intolerable discomfort, followed by 16.7 percent were found to have noticeable discomfort, but 5 percent did not have any discomfort. 4.2 percent complained about tolerable bottom pain, followed by complaint of intolerable discomfort was recorded from 2.5 percent respondents, 93.3 percent denied to have any discomfort in bottom. 5.8 percent respondents were found to have tolerable discomfort in both left and right lower arm, but 94.2 percent did not find any discomfort in left and right lower arm. Majority of 85.8 percent respondent complain about tolerable discomfort in left and right wrist, followed by 10 percent found noticeable discomfort, only 4.2 denied to have any discomfort. 97.5 percent respondents were found to have tolerable discomfort in both left and right hand. Only 0.8 percent found to have noticeable discomfort and rest of 1.7 percent did not found any discomfort in left and right hand. 25 percent complain about tolerable discomfort in left and right knee, followed by 19.2 percent with noticeable discomfort, followed by 7.5 percent complaint of intolerable discomfort in both knees, but 48.3 did not complaint about any discomfort in knees.

It can be concluded that majority of the respondents had tolerable discomfort in back, bottom, left and right hand and left and right wrist. This discomfort may be due to awkward bending of body for longer period of time, repetitive movement of hands and wrist might be the reason for tolerable discomfort. According to the data in table 4.6 it was clear that respondents felt discomfort only in lower neck, left shoulder, right shoulder, back, buttock, bottom, left lower arm, right lower arm, left wrist, right wrist, left hand, right hand, left knee, right knee. This may be due to awkward posture or repetitive motion of body parts for a longer period of time may be the reason for these discomforts.

Data in (Table 5) also reveals about the percentage of respondents having no discomfort in body parts like upper neck, left upper arm, right upper arm, waist, left elbow, right elbow, left thigh, right thigh, left calf, right calf, left ankle, right ankle, left foot, right foot. It was also recorded that few respondents complain of intolerable discomfort in the left shoulder, right shoulder, buttock, bottom, left knee, and right knee. 
Table 5: Percentage distribution of Body Parts Discomfort among women in papad making activity

\begin{tabular}{|c|c|c|c|c|c|c|c|c|c|c|c|}
\hline \multirow{2}{*}{$\begin{array}{l}\text { Sl. } \\
\text { No. }\end{array}$} & \multirow[t]{2}{*}{ Body parts } & \multicolumn{2}{|c|}{$1=$ No discomfort } & \multicolumn{2}{|c|}{$\begin{array}{c}2=\begin{array}{c}\text { Just noticeable } \\
\text { discomfort }\end{array} \\
\end{array}$} & \multicolumn{2}{|c|}{$\begin{array}{c}\text { 3= noticeable } \\
\text { discomfort }\end{array}$} & \multicolumn{2}{|c|}{ 4=Tolerable discomfort } & \multicolumn{2}{|c|}{$\begin{array}{c}5=\text { Intolerable } \\
\text { discomfort }\end{array}$} \\
\hline & & $\mathbf{F}$ & $\%$ & $\mathbf{F}$ & $\%$ & $\mathbf{f}$ & $\%$ & $\mathbf{f}$ & $\%$ & $\mathbf{F}$ & $\%$ \\
\hline 1 & Lower neck & 99 & 82.5 & - & - & 8 & 6.7 & 13 & 10.8 & - & - \\
\hline 2 & Left shoulder & 46 & 38.3 & - & - & 38 & 31.7 & 30 & 25.0 & 5 & 5.0 \\
\hline 3 & Right shoulder & 46 & 38.3 & - & - & 38 & 31.7 & 30 & 25.0 & 6 & 5.0 \\
\hline 4 & Back & 12 & 10.0 & - & - & 5 & 4.2 & 103 & 85.8 & - & - \\
\hline 5 & Buttock & 6 & 5.0 & - & - & 20 & 16.7 & 71 & 59.2 & 23 & 19.2 \\
\hline 6 & Bottom & 112 & 93.3 & - & - & - & - & 5 & 4.2 & 3 & 2.5 \\
\hline 7 & Left lower arm & 113 & 94.2 & - & - & - & - & 7 & 5.8 & - & - \\
\hline 8 & Right lower arm & 113 & 94.2 & - & - & - & - & 7 & 5.8 & - & - \\
\hline 9 & Left wrist & 5 & 4.2 & - & - & 12 & 10.0 & 103 & 85.8 & - & - \\
\hline 10 & Right wrist & 5 & 4.2 & - & - & 12 & 10.0 & 103 & 85.8 & - & - \\
\hline 11 & Left hand & 2 & 1.7 & - & - & 1 & .8 & 117 & 97.5 & - & - \\
\hline 12 & Right hand & 2 & 1.7 & - & - & 1 & .8 & 117 & 97.5 & - & - \\
\hline 13 & Left knee & 58 & 48.3 & - & - & 23 & 19.2 & 30 & 25 & 9 & 7.5 \\
\hline 14 & Right knee & 58 & 48.3 & - & - & 23 & 19.2 & 30 & 25 & 9 & 7.5 \\
\hline
\end{tabular}

Ranking of Body Parts Discomfort faced by the respondents in papad making activity

The ranking was done based on Body Parts Discomfort faced by women in papad making activity. Based on (Table 6) it was clear that the majority of respondents had pain in the left and right hand so it was ranked I, pain in both hands may be because of repetitive movement of hands for longer periods of time during rolling, and ball making activity. Continuous bending posture for a longer period of time while performing different activities may cause stress and pain in buttocks which was reported as discomfort and was ranked II. It was observed that movement of the wrist was found to be maximum in all activities performed by the women in papad making activity, therefore rhythmic adduction and abduction of wrists during different activities might result in discomfort in both wrists and was ranked III. Back pain was ranked IV discomfort in the back might be due to continuous sitting posture without back support.

Table 6: Ranking of Body Parts Discomfort faced by respondents in papad making activity

\begin{tabular}{|c|c|c|c|c|c|c|c|c|}
\hline Sl. No & Body parts & $\begin{array}{c}\text { No Discomfort } \\
\text { (1) }\end{array}$ & \begin{tabular}{|c|} 
Noticeable \\
discomfort (3)
\end{tabular} & $\begin{array}{c}\text { Tolerable } \\
\text { discomfort (4) }\end{array}$ & $\begin{array}{c}\text { Intolerable } \\
\text { discomfort (5) }\end{array}$ & $\begin{array}{l}\text { Total } \\
\text { score }\end{array}$ & Mean & Rank \\
\hline 1 & Lower neck & 99 & 8 & 13 & - & 178 & 1.48 & VII \\
\hline 2 & Left shoulder & 46 & 38 & 30 & 6 & 315 & 2.62 & \multirow{2}{*}{ V } \\
\hline 3 & Right shoulder & 46 & 38 & 30 & 6 & 315 & 2.62 & \\
\hline 4 & Back & 12 & 5 & 103 & - & 439 & 3.65 & IV \\
\hline 5 & Buttock & 6 & 20 & 71 & 23 & 465 & 3.87 & II \\
\hline 6 & Bottom & 112 & - & 5 & 3 & 147 & 1.25 & VIII \\
\hline 7 & Left lower arm & 113 & - & 7 & - & 141 & 1.17 & \multirow{2}{*}{ IX } \\
\hline 8 & Right lower arm & 113 & - & 7 & - & 141 & 1.17 & \\
\hline 9 & Left wrist & 5 & 12 & 103 & - & 453 & 3.77 & \multirow{2}{*}{ III } \\
\hline 10 & Right wrist & 5 & 12 & 103 & - & 453 & 3.77 & \\
\hline 11 & Left hand & 2 & 1 & 117 & - & 473 & 3.94 & \multirow{2}{*}{ I } \\
\hline 12 & Right hand & 2 & 1 & 117 & - & 473 & 3.94 & \\
\hline 13 & Left knee & 58 & 23 & 30 & 9 & 292 & 2.43 & \multirow{2}{*}{ VI } \\
\hline 14 & Right knee & 58 & 23 & 30 & 9 & 292 & 2.43 & \\
\hline
\end{tabular}

All sub-activities were performed with the hand which requires continues hand motion which might be the reason for shoulder pain and was ranked V. During drying activity continues bending was observed and another activity was performed by assuming a sitting posture which requires bending of the knee for a longer period of time this might be the cause for knee pain which was ranked VI. Activities were done with bending head down during rolling, ball making and packaging continues bending of the head may affect the spine of neck and was perceived as discomfort by the women workers involved in papad making activity and was ranked VII. The discomfort was perceived in the bottom part of the respondent and was ranked after the lower neck i.e., VIII. The discomfort was faced in lower arms and was ranked IX according to (Table 6). were found to assume different awkward postures during different sub activities among which rolling activity was found as 'very heavy' activity. It could be concluded that awkward postures for longer durations results in discomfort in different body parts and development of pain in lower neck, shoulders, back bottom, lower arm, wrist, hands and knees leads to musculoskeletal disorder among these women. Ergonomic intervention is considered to be necessary for the postural health of the workers. Hence proper intervention through information in vernacular language if given for corrective measures and use of labour saving tools and equipments for faster work will help them from assuming improper postures for longer period of time. It will also help to increase productivity and save time and other benefits in the long run.

\section{Conclusion}

Women involved in papad making activity on daily basis 


\section{Reference}

1. Maity P, Sujaya D, Pal A, Mahata H, Chatterjee M, Dhara PC. Identification of A Suitable Working Posture For Female Workers Engaged In Golden Thread Work. International Journal of Occupational Safety and Health 2014;4(2):24-33.

2. Borah S. Ergonomic Assessment of Drudgery of Women Worker Involved In Cashew Nut Processing Factory In Meghalaya, India 6th International Conference on Applied Human Factors and Ergonomics (AHFE 2015) and The Affiliated Conferences, AHFE 2015 Procedia Manufacturing 2015;3:4665-4672.

3. Montakarn C, Nuttika N. Physical Activity Levels and Prevalence of Low Back Pain in Thai Call-Center Operators. Indian J Occup. Environ. MedI 2016;20:125128.

4. Sarkar K, Dev S, Das T, Chakrabarty S, Gangopadhyay S. Examination of Postures and Frequency of Musculoskeletal Disorders Among Manual Workers In Calcutta. India. Int. J Occup. Environ. Health 2016;22(2):151-158.

5. Pal A, Dhara PC. Work Related Musculoskeletal Disorders and Postural Stress of The Women Cultivators Engaged In Uprooting Job of Rice Cultivation. Indian Journal of Occupational and Environmental Medicine 2018;22:163-169.

6. Chaiklieng S. Health Risk Assessment on Musculoskeletal Disorder Among Potato Chips Processing Workers. Plos One 2019;14(12):e0224980.

7. Singh D, Kaur J. Ergonomic Risk Factors in Women Workers Involved in Handicraft Industry of Patiala District: Volume IX: Aging, Gender And Work, Anthropometry. Ergonomics For Children And Educational Environments 2019. 10.1007/978-3-31996065-4_43.

8. Rekha B, Marbate T, Gedam C, Bhave S, Umanjali D. Prevalence of Musculoskeletal Pain and Postural Deformity in Papad Making Women. Pain Studies and Treatment 2019;7(02):21-31. 